\title{
Interferon-stimulated gene factor 3 complex is required for the induction of sterile $\alpha$ motif and HD domain-containing protein 1 expression by interferon- $\alpha$ in SMMC-7721 cells
}

\author{
MENGYING ZHU ${ }^{1}$, JINSEN LU ${ }^{1}$, XIAOWAN DONG ${ }^{1}$, NAN ZHENG ${ }^{1}$, TINGTING LI ${ }^{1}$, ZHANGMING CHEN ${ }^{1}$, \\ XIANG PAN ${ }^{1}$, YONGJI ZHU ${ }^{1}$, HAI YAN ${ }^{1}$, YUXIAN SHEN ${ }^{2}$, SONGCHENG YING $^{1}$ and CHUNSONG HU ${ }^{1}$ \\ ${ }^{1}$ Department of Immunology, School of Basic Medical Sciences, Anhui Medical University; \\ ${ }^{2}$ Department of Pharmacology, School of Basic Medical Sciences and Biopharmaceutical Research Institute, \\ Anhui Medical University, Hefei, Anhui 230032, P.R. China
}

Received December 6, 2014; Accepted August 24, 2015

DOI: $10.3892 / \mathrm{mmr} .2015 .4332$

\begin{abstract}
Sterile $\alpha$ motif and HD domain-containing protein 1 (SAMHD1) is a novel intrinsic restriction factor that inhibits the replication of certain retroviruses and DNA viruses through its deoxynucleoside triphosphate triphosphohydrolase activity. A previous study by our group showed that SAMHD1 restrained hepatitis $B$ virus replication and interferon (IFN)- $\alpha$ induced SAMHD1 expression in liver cells. However the mechanisms of SAMHD1 upregulation by IFN- $\alpha$ in liver cells have remained elusive. The present study demonstrated that IFN- $\alpha$ treatment increased SAMHD1 mRNA levels in SMMC-7721 cells in a time-dependent manner. Knockdown of STAT1 inhibited the induction of SAMHD1 expression by IFN- $\alpha$ in SMMC-7721 cells. STAT2 silencing also suppressed the induction of SAMHD1 expression by IFN- $\alpha$ in SMMC-7721 cells. Furthermore, the induction of SAMHD1 expression in SMMC-7721 cells by IFN- $\alpha$ was found to be dependent on IFN-regulatory factor 9 (IRF9). In conclusion, these results suggested that the interferon-stimulated gene factor 3 complex, which consists of STAT1, STAT2 and IRF9, is required for the induction of SAMHD1 expression by IFN- $\alpha$ in SMMC-7721 cells.
\end{abstract}

\section{Introduction}

Primates and humans possess intrinsic immunity to inhibit viral replication immediately and directly $(1,2)$. The sterile

Correspondence to: Dr Songcheng Ying or Professor Chunsong Hu, Department of Immunology, School of Basic Medical Sciences, Anhui Medical University, 81 Meishan Road, Hefei, Anhui 230032, P.R. China

E-mail: yingsc@ahmu.edu.cn

E-mail: hcs2828@263.net

Key words: interferon-stimulated gene factor 3, sterile $\alpha$ motif and HD domain-containing protein 1 , interferon- $\alpha$, SMMC-7721 cells $\alpha$ motif and HD domain-containing protein 1 (SAMHD1) is a newly identified anti-viral factor in this immunity (3). SAMHD1 is a deoxynucleoside triphosphate triphosphohydrolase (dNTPase) that depletes the intracellular pool of deoxynucleoside triphosphates (dNTPs) and restricts the replication of human immunodeficiency virus type 1 (HIV-1) in non-cycling myeloid cells (4-8). Most recently, it was discovered that SAMHD1 prevented HIV-1 infection by directly degrading HIV-1 RNA through its ribonuclease activity (9).

Besides HIV-1, SAMHD1 has the ability to restrict other retroviruses, including simian immunodeficiency virus, feline immunodeficiency virus, bovine immunodeficiency virus, equine infectious anemia virus, murine leukemia virus (MLV), Mason Pfizer monkey virus, Rous sarcoma virus and human T-cell leukemia virus type 1 (10-12). In addition, it has been discovered that SAMHD1 restricts two DNA viruses, herpes simplex virus type 1 (HSV-1) and vaccinia virus, in non-dividing myeloid cells $(13,14)$. A previous study by our group showed that SAMHD1 also restrained the replication of another DNA virus, hepatitis B virus (HBV) (15). Most recently, porcine SAMHD1 was demonstrated to block the replication of porcine reproductive and respiratory syndrome virus, a positive-stranded RNA virus, in MARC-145 cells (16). Thus, SAMHD1 is a relatively broad-spectrum anti-viral factor against numerous types of virus.

Interferons (IFNs) often strongly induce the expression of restriction factors during the anti-viral state (17). It is well known that type I IFNs may induce the expression of IFN-stimulated genes (ISGs) through the canonical and non-canonical signaling pathway $(18,19)$. In the canonical pathway, the binding of IFN- $\alpha$ to the IFN- $\alpha$ receptor results in the activation of Janus kinase (JAK) members Tyk2 and JAK1, which phosphorylate signal transducer and activator of transcription 1 (STAT1) and STAT2. Phosphorylated STAT1 and STAT2 dimerize and further assemble with IFN-regulatory factor 9 (IRF9) to form a transcription factor complex called IFN-stimulated gene factor 3 (ISGF3). ISGF3 binds to IFN-stimulated response elements (ISRE) and directly activates the transcription of ISGs. Accumulating evidence has 
shown that non-canonical IFN- $\alpha$ signaling pathways exist and function beyond ISGF3 (19).

Apolipoprotein B mRNA-editing enzyme catalytic polypeptide-like $3 \mathrm{G}$ protein is a well-studied anti-viral factor that may be induced by IFN- $\alpha$ in liver cells through a novel STAT1-independent signaling pathway (20). A previous study by our group reported that IFN- $\alpha$ induced SAMHD1 expression in liver cells (15). However, the mechanism of how SAMHD1 expression is upregulated by IFN- $\alpha$ in liver cells has remained elusive. The present study found that ISGF3 complex was required for the induction of SAMHD1 expression by IFN- $\alpha$ in SMMC-7721 cells, suggesting that IFN- $\alpha$ induced SAMHD1 expression in liver cells through the canonical IFN- $\alpha$ signaling pathway.

\section{Materials and methods}

Cell culture, IFN- $\alpha$ stimulation and transfection. SMMC-7721 cells (Type Culture Collection of the Chinese Academy of Sciences, Shanghai, China) were cultured in Dulbecco's modified Eagle's medium supplemented with $10 \%$ (v/v) fetal calf serum (Zhejiang Tianhang Biological Technology Co., Ltd., Hangzhou, China), in a $37^{\circ} \mathrm{C}$ incubator containing $5 \%$ $\mathrm{CO}_{2}$. SMMC-7721 cells were plated in six-well plates $\left(4 \times 10^{5}\right.$ cells/well) and grown to $80-90 \%$ confluency. Then cells were treated with 1,000 IU/ml IFN- $\alpha$ (Anhui Anke Biotechnology Co., Ltd., Hefei, China) for 0, 2, 4, 6, 8, 10 or 24 h, respectively, and were then harvested for reverse-transcription quantitative polymerase chain reaction (RT-qPCR) analysis. SMMC-7721 cells were plated in 12 -well plates $\left(2 \times 10^{5}\right.$ cells/well $)$ and transfected with small interfering (si)RNAs (negative control siRNA, STAT1 siRNA, STAT2 siRNA or IRF9 siRNA) using

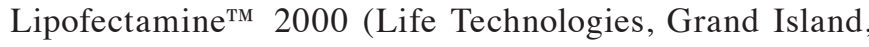
$\mathrm{NY}$, USA) according to the manufacturer's instructions. $48 \mathrm{~h}$ post-transfection, cells were further treated with $1,000 \mathrm{IU} / \mathrm{ml}$ IFN- $\alpha$ for $10 \mathrm{~h}$. Cells were harvested for western blot and RT-qPCR analyses.

RNA interference. RNA interference against STAT1, STAT2 and IRF9 was performed using known siRNAs which had been used in previous studies (21-23). The siRNAs had the following sequences: STAT1 sense, 5'-r(CACGAGACCAAU GGUGUGG)d(TT)-3' and anti-sense, 5'-r(CCACACCAU UGGUCUCGUG)d(TT)-3'; STAT2 sense, 5'-GGACUG AGUUGCCUGGUUAUU-3' and anti-sense, 5'-(P)UAA CCAGGCAACUCAGUCCUU-3'; IRF9 sense, 5'-GCAGAG ACUUGGUCAGGUAUU-3' and anti-sense, 5'-(P)UACCUG ACCAAGUCUCUGCUU-3'; negative control sense, 5'-UUC UCCGAACGUGUCACGUTT-3' and anti-sense, 5'-ACG UGACACGUUCGGAGAATT-3'. All of these siRNAs were synthesized by Shanghai GenePharma Co., Ltd. (Shanghai, China). SMMC-7721 cells were transfected with the respective siRNAs and incubated for $48 \mathrm{~h}$. After further stimulation with IFN- $\alpha$, cells were harvested for western blot and RT-qPCR.

Western blot analysis. After RNA interference and IFN- $\alpha$ treatment, SMMC-7721 cells were lysed in radioimmunoprecipitation assay lysis buffer (Beyotime Institute of Biotechnology, Haimen, China). The protein concentration of the supernatants was determined using a bicinchoninic acid kit (cat. no. P00125;
Beyotime Institute of Biotechnology) after centrifugation at $12,000 \mathrm{~g}$ for $5 \mathrm{~min}, 20 \mu \mathrm{g}$ protein was loaded onto each lane and separated by $10 \%$ SDS-PAGE. Then proteins were transferred onto Immuno-Blot polyvinylidene fluoride membranes (Millipore, Billerica, MA, USA). Following blocking, the membranes were incubated with rabbit anti-STAT1 polyclonal antibody (cat. no. 10144-2-AP; 1:1,000), rabbit anti-STAT2 polyclonal antibody (cat. no. 16674-1-AP; 1:1,000) or rabbit anti-IRF9 polyclonal antibody (cat. no. 14167-1-AP; 1:1,000) at $4{ }^{\circ} \mathrm{C}$ overnight, respectively. These primary antibodies were purchased from Proteintech Group (Wuhan, China). $\beta$-actin was used as a loading control and mouse anti- $\beta$-actin monoclonal antibody (cat. no. TA-09; 1:500) was obtained from Beijing ZSGB-Biotechnology Co., Ltd. (Beijing, China) and incubated at $4^{\circ} \mathrm{C}$ overnight. The following secondary antibodies were used in the present study: Horseradish peroxidase-conjugated goat anti-rabbit immunoglobulin IgG (cat. no. BL003A; 1:10,000), incubated at room temperature for $1 \mathrm{~h}$, and goat anti-mouse IgG (cat. no. BL001A; 1:10,000), incubated at room temperature for $1 \mathrm{~h}$ (Biosharp Co., Hefei, China). Immunoreactive proteins were visualized using the Super Signal West Femto kit (cat. no. 34094; Thermo Fisher Scientific, Waltham, MA, USA) and images were captured using the digital gel image analysis system (4500SF; Tanon Science \& Technology Co., Ltd., Shanghai, China).

RT-qPCR analysis. Total RNA was isolated from SMMC-7721 cells after RNA interference and IFN- $\alpha$ treatment using TRIzol ${ }^{\circledR}$ reagent (Life Technologies). cDNAs were then prepared by reverse transcription from total RNA using M-MLV Reverse Transcriptase (Life Technologies). Real-time qPCR experiments were performed in $0.2 \mathrm{ml}$ 96-well PCR plates using TaqMan ${ }^{\circledR}$ Gene Expression Master Mix (Life Technologies). Each reaction well in the 96-well PCR plates contained a total volume of $20 \mu \mathrm{l}$ : $1 \mu \mathrm{l}$ 20xTaqMan ${ }^{\circledR}$ Gene Expression Assay, $10 \mu 1$ 2X TaqMan ${ }^{\circledR}$ Gene Expression Master Mix, $4 \mu \mathrm{l}$ cDNA template (500 ng) and $5 \mu 1$ RNase-free water. The following primer/probe sets were utilized in the present study: SAMHD1 (Hs00210019_m1), ISG15 (Hs00192713_m1) and GAPDH (Hs99999905_m1) (Life Technologies). Real-time PCR reactions were performed using StepOnePlus ${ }^{\mathrm{TM}}$ Real-time PCR System (Life Technologies). Thermal cycling conditions were as follows: $2 \mathrm{~min}$ at $50^{\circ} \mathrm{C}$ and $10 \mathrm{~min}$ at $95^{\circ} \mathrm{C}$, followed by 40 cycles of $15 \mathrm{sec}$ at $95^{\circ} \mathrm{C}$ and $1 \mathrm{~min}$ at $60^{\circ} \mathrm{C}$. Data analysis and quantification were performed using the $2^{-\Delta \Delta \mathrm{CT}}$ comparative method (24).

Statistical analysis. Values are expressed as the mean \pm standard deviation. Statistical significance of differences between STAT1, STAT2 or IRF9 siRNA-transfected groups with IFN- $\alpha$-treatment and the control siRNA-transfected group with IFN- $\alpha$ treatment were analyzed by Student's $t$ test using GraphPad Prism 5 (GraphPad Inc., La Jolla, CA, USA). P<0.05 was considered to indicate a statistically significant difference between values.

\section{Results}

IFN- $\alpha$ treatment increases SAMHDI mRNA levels in SMMC-7721 cells in a time-dependent manner. A previous 

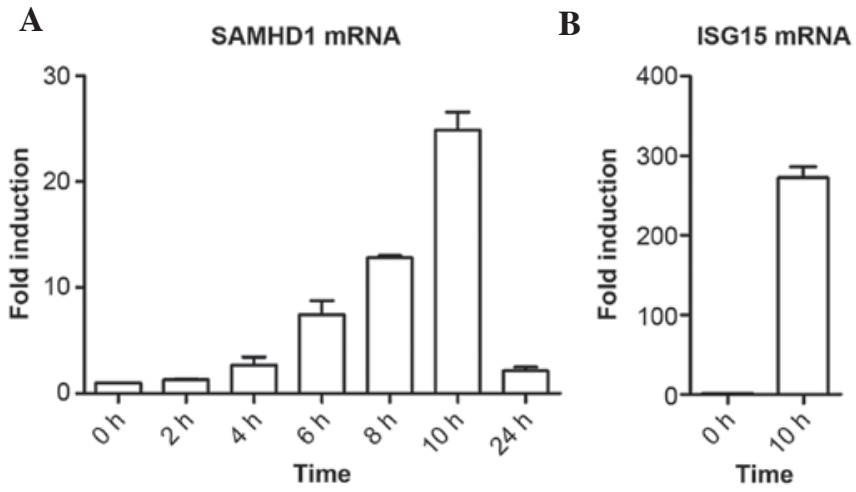

Figure 1. IFN- $\alpha$ induces SAMHD1 expression at the mRNA level in SMMC-7721 cells in a time-dependent manner. (A) SMMC-7721 cells were treated with $1,000 \mathrm{IU} / \mathrm{ml} \mathrm{IFN}-\alpha$ and harvested following incubation for $0,2,4,6,8,10$ or $24 \mathrm{~h}$ for assessment of SAMHD1 mRNA levels using RT-qPCR. (B) SMMC-7721 cells were stimulated with 1,000 IU $/ \mathrm{ml} \mathrm{IFN- \alpha}$ for $10 \mathrm{~h}$ and the mRNA levels of the known IFN- $\alpha$-responsive ISG15 were detected using RT-qPCR method. Results are representative of at least three independent experiments with triplicate samples, and are expressed as the mean \pm standard deviation. IFN, interferon; SAMHD1, sterile $\alpha$ motif and HD domain-containing protein 1; ISG15, interferon-stimulated gene factor 3; RT-qPCR, reverse-transcription quantitative polymerase chain reaction.

A

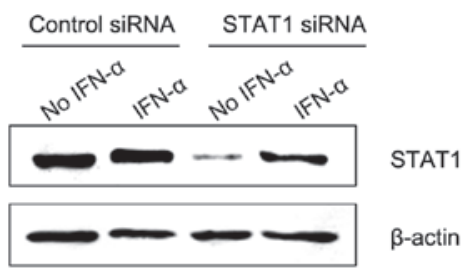

B

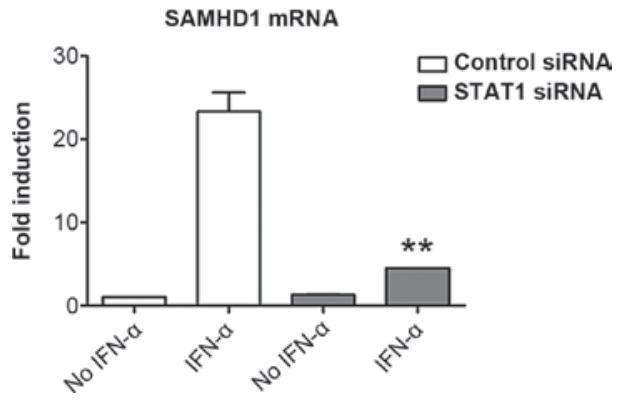

Figure 2. STAT1 downregulation blocks the induction of SAMHD1 expression by IFN- $\alpha$ in SMMC-7721 cells. STAT1 siRNA or control siRNA was transfected into SMMC-7721 cells for $48 \mathrm{~h}$, which were subsequently incubated with or without $1,000 \mathrm{IU} / \mathrm{ml} \mathrm{IFN}-\alpha$ for $10 \mathrm{~h}$. The cells were harvested and (A) STAT1 protein expression was detected by western blot analysis using anti-STAT1 polyclonal antibody and (B) SAMHD1 mRNA levels were determined by reverse-transcription quantitative polymerase chain reaction. Results are representative of at least three independent experiments with triplicate samples, and are expressed as the mean \pm standard deviation. ${ }^{* *} \mathrm{P}<0.01$, STAT1 siRNA-transfected group with IFN- $\alpha$ treatment vs. control siRNA-transfected group with IFN- $\alpha$ treatment. IFN, interferon; siRNA, small interfering RNA; STAT, signal transducer and enhancer of transcription; SAMHD1, sterile $\alpha$ motif and HD domain-containing protein 1.

study by our group identified that IFN- $\alpha$ induced SAMHD1 expression at the protein level in liver cells by using western blot analysis (15). The present study further assessed whether IFN- $\alpha$ induced SAMHD1 expression at the mRNA level using RT-qPCR analysis. The results showed that IFN- $\alpha$ treatment increased the mRNA levels of SAMHD1 in
SMMC-7721 cells in a time-dependent manner (Fig. 1A). The fold induction of SAMHD1 mRNA expression by IFN- $\alpha$ was 25 -fold following $10 \mathrm{~h}$ of incubation, while at $24 \mathrm{~h}$, it was reduced to $\sim$ two-fold of the levels at the beginning of the experiment. As the positive control, ISG15, a the well-defined IFN- $\alpha$-responsive gene, was used. ISG15 mRNA levels in SMMC-7721 cells were markedly upregulated by IFN- $\alpha$ following $10 \mathrm{~h}$ of incubation (Fig. 1B). Together with the results of the previous study by our group (15), the results of the present study demonstrated that IFN- $\alpha$ induced SAMHD1 expression in SMMC-7721 cells at the mRNA as well as the protein level in a time-dependent manner.

Induction of SAMHD1 expression in SMMC-7721 cells by IFN- $\alpha$ is inhibited by STAT1 knockdown. ISGF3 transcription factor complex consists of STAT1, STAT2 and IRF9, which are involved in the canonical type I interferon signaling pathway (19). To explore the role of ISGF3 in the induction of SAMHD1 expression by IFN- $\alpha$, the present study firstly downregulated the expression of STAT1 in SMMC-7721 cells by RNA interference and then evaluated its influence in the induction of SAMHD1 expression by IFN- $\alpha$ using RT-qPCR. The results showed that STAT1 was expressed in SMMC7-7721 cells and that IFN- $\alpha$ treatment induced its expression (Fig. 2A). This phenomenon was similar to that reported by a previous study (25). STAT1-specific siRNA efficiently silenced STAT1 expression in SMMC-7721 cells, although IFN- $\alpha$ treatment partially abrogated the effects of STAT1 siRNA, suggesting that STAT1-knockdown was efficient (Fig. 2A). Of note, STAT1 siRNA treatment significantly reduced the induction of SAMHD1 expression by IFN- $\alpha$ in SMMC-7721 cells, while control siRNA had no effect on IFN- $\alpha$-induced SAMHD1 expression (Fig. 2B). These results indicated that STAT1 was required for the induction of SAMHD1 expression by IFN- $\alpha$ in SMMC-7721 cells.

STAT2 silencing suppresses the induction of SAMHD1 expression by IFN- $\alpha$ in SMMC-7721 cells. Next, the present study determined the role of STAT2 in the induction of SAMHD1 expression by IFN- $\alpha$ in SMMC-7721 cells. Similarly to the results on STAT1, it was shown that STAT2 was also expressed in SMMC-7721 cells and that IFN- $\alpha$ treatment induced its expression (Fig. 3A). STAT2 expression was almost completely silenced by STAT2-specific siRNA in the group without IFN- $\alpha$ treatment. With IFN- $\alpha$ treatment, STAT2 protein levels in the STAT2 siRNA-transfected cells was obviously lower than those in control siRNA-transfected cells (Fig. 3A). These results demonstrated that STAT2 siRNA successfully inhibited STAT2 expression in SMMC-7721 cells. Of note, the results showed that silencing of STAT2 expression markedly reduced the induction of SAMHD1 expression by IFN- $\alpha$ in SMMC-7721 cells (Fig. 3B), indicating that STAT2 was involved in the signaling pathway of IFN- $\alpha$-induced SAMHD1 expression.

Inductionof SAMHD1 expression byIFN- $\alpha$ isIRF9-dependent in SMMC-7721 cells. The present study further tested whether IRF9 was also involved in the induction of the expression of SAMHD1 by IFN- $\alpha$ in SMMC-7721 cells. The 
A

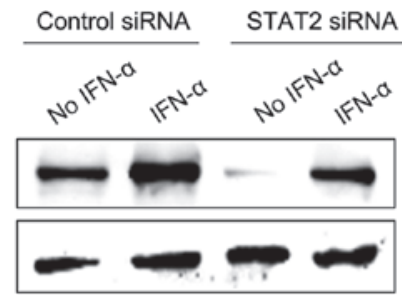

STAT2

$\beta$-actin

B

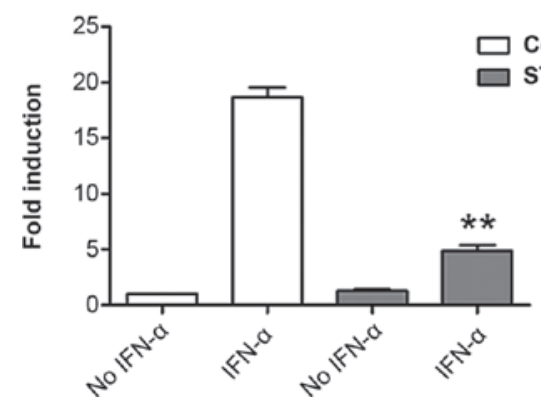

Figure 3. STAT2 silencing reduces the induction of SAMHD1 expression by IFN- $\alpha$ in SMMC-7721 cells. STAT2 siRNA or control siRNA was transfected into SMMC-7721 cells for $48 \mathrm{~h}$ and cells were subsequently incubated with or without $1,000 \mathrm{IU} / \mathrm{ml} \mathrm{IFN- \alpha}$ for $10 \mathrm{~h}$. The cells were harvested and (A) STAT2 protein expression was detected by western blot analysis using anti-STAT2 polyclonal antibody and (B) SAMHD1 mRNA levels were determined by reverse-transcription quantitative polymerase chain reaction. Results are representative of at least three independent experiments with triplicate samples, and are expressed as the mean \pm standard deviation. ${ }^{* *} \mathrm{P}<0.01$, STAT2 siRNA-transfected group with IFN- $\alpha$ treatment vs. control siRNA-transfected group with IFN- $\alpha$ treatment. IFN, interferon; siRNA, small interfering RNA; STAT, signal transducer and enhancer of transcription; SAMHD1, sterile $\alpha$ motif and HD domain-containing protein 1 .

\section{A}
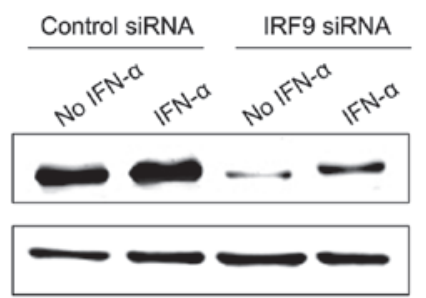

IRF9

$\beta$-actin

\section{B}

SAMHD1 mRNA

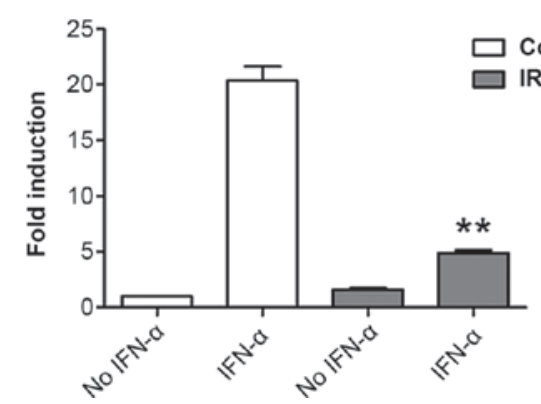

Figure 4. Induction of SAMHD1 expression by IFN- $\alpha$ is IRF9-dependent in SMMC-7721 cells. IRF9 siRNA or control siRNA was transfected into SMMC-7721 cells for $48 \mathrm{~h}$ and cells were subsequently incubated with or without $1,000 \mathrm{IU} / \mathrm{ml} \mathrm{IFN}-\alpha$ for $10 \mathrm{~h}$. Then cells were harvested and (A) IRF9 protein expression was detected by western blot analysis using anti-IRF9 polyclonal antibody and (B) SAMHD1 mRNA levels were determined by reverse-transcription quantitative polymerase chain reaction. Results are representative of at least three independent experiments with triplicate samples, and are expressed as the mean \pm standard deviation. ${ }^{* *} \mathrm{P}<0.01$, IRF9 siRNA-transfected group with IFN- $\alpha$ treatment vs. control siRNA-transfected group with IFN- $\alpha$ treatment. IFN, interferon; siRNA, small interfering RNA; STAT, signal transducer and enhancer of transcription; SAMHD1, sterile $\alpha$ motif and HD domain-containing protein 1; IRF9, IFN-regulatory factor 9. results showed that IRF9 was expressed in SMMC-7721 cells and that IFN- $\alpha$ treatment markedly enhanced its expression (Fig. 4A). Of note, IRF9 siRNA markedly inhibited IRF9 expression in the presence or absence of IFN- $\alpha$ (Fig. 4A). More importantly, siRNA-mediated knockdown of IRF9 largely suppressed the induction of SAMHD1 expression by IFN- $\alpha$ in SMMC-7721 cells. These results revealed that IRF9 was required for the induction of SAMHD1 expression by IFN- $\alpha$ in SMMC-7721 cells.

\section{Discussion}

It has been demonstrated that IFN- $\alpha$ induces SAMHD1 expression in monocytic cells (26), U87-MG cells (27), human embryonic 293T cells and HeLa cells (28). A previous study showed that SAMHD1 expression was obviously induced by IFN- $\alpha$ at the protein level in SMMC-7721 and BEL-7402 hepatoma cell lines (15). However, the signaling pathway via which the induction of SAMHD1 expression by IFN- $\alpha$ is mediated has remained elusive. The formation of ISGF3 transcription factor complex comprising STAT1, STAT2 and IRF9 is a hallmark of the canonical type I IFN signaling pathway (19). The present study revealed that silencing of STAT1, STAT2 and IRF9 by their specific siRNAs blocked IFN- $\alpha$-induced SAMHD1 expression in SMMC-7721 cells, indicating that the ISGF3 complex was required for the induction of SAMHD1 expression by IFN- $\alpha$ in SMMC-7721 cells.

Previous studies showed that STAT1, STAT2 and IRF9 mRNA as well as protein levels were upregulated by IFN- $\alpha$ treatment in human hepatoma HepG2 cells (29), human peripheral blood mononuclear cells and macrophages (30). Consistent with these results, the present study indicated that IFN- $\alpha$ upregulated STAT1, STAT2 and IRF9 in human hepatoma SMMC-7721 cells. However, STAT1, STAT2 and IRF9 expression levels in the specific siRNA-transfected groups were markedly lower than those in the control siRNA-transfected groups even after IFN- $\alpha$ stimulation, indicating that these siRNAs were efficient regardless of the presence or absence of IFN- $\alpha$.

In the classical type I IFN signaling pathway, ISGF3 binds to the consensus ISRE DNA sequence and then activates gene expression. Whether ISRE is located upstream of the SAMHD1 gene requires further investigation. It has been reported that STAT1 may be phosphorylated by inhibitor of nuclear factor $\kappa \mathrm{B}$ kinase $\varepsilon(\mathrm{IKK} \varepsilon)$ and certain type I IFN-stimulated genes remain inactive in the absence of IKKe, indicated by ISGF3 not binding to the promoter elements of these genes (31). Further studies are required to explore whether IKKe or JAKs are engaged in the formation of ISGF3 in IFN- $\alpha$-induced SAMHD1 expression in SMMC-7721 cells.

Zhang et al (29) reported that the ISGF3 complex has a key role in IFN- $\alpha$-mediated anti-HBV responses in human hepatoma cells. The present study demonstrated that IFN- $\alpha$ induced SAMHD1 expression through the ISGF3 complex in SMMC-7721 cells. Together with the results of a previous study by our group (15), it may be concluded that SAMHD1 is induced by IFN- $\alpha$ in liver cells through the canonical IFN- $\alpha$ signaling pathway and inhibits HBV replication during IFN- $\alpha$ treatment of HBV-infected patients. 


\section{Acknowledgements}

The present study was supported by grants from the Natural Science Foundation of Anhui Province (no. 1208085MH134 to C.H. and no. $158085 \mathrm{MH} 158$ to S.Y) and the Research Fund of Anhui Medical University (no. 0116025101 to S.Y.).

\section{References}

1. Yan $\mathrm{N}$ and Chen $\mathrm{ZJ}$ : Intrinsic antiviral immunity. Nat Immunol 13: 214-222, 2012.

2. Kawamura T, Ogawa Y, Aoki R and Shimada S: Innate and intrinsic antiviral immunity in skin. J Dermatol Sci 75: 159-166, 2014.

3. Chen Z, Zhang L and Ying S: SAMHD1: A novel antiviral factor in intrinsic immunity. Future Microbiol 7: 1117-1126, 2012.

4. Laguette N, Sobhian B, Casartelli N, Ringeard M,Chable-BessiaC, Ségéral E, Yatim A, Emiliani S, Schwartz O and Benkirane M: SAMHD1 is the dendritic- and myeloid-cell-specific HIV-1 restriction factor counteracted by Vpx. Nature 474: 654-657, 2011.

5. Hrecka K, Hao C, Gierszewska M, Swanson SK, Kesik-Brodacka M, Srivastava S, Florens L, Washburn MP and Skowronski J: Vpx relieves inhibition of HIV-1 infection of macrophages mediated by the SAMHD1 protein. Nature 474 : 658-661, 2011

6. Goldstone DC, Ennis-Adeniran V, Hedden JJ, Groom HC, Rice GI, Christodoulou E, Walker PA, Kelly G, Haire LF, Yap MW, et al: HIV-1 restriction factor SAMHD1 is a deoxynucleoside triphosphate triphosphohydrolase. Nature 480: 379-382, 2011.

7. Powell RD, Holland PJ, Hollis $\mathrm{T}$ and Perrino FW: Aicardi-Goutieres syndrome gene and HIV-1 restriction factor SAMHD1 is a dGTP-regulated deoxynucleotide triphosphohydrolase. J Biol Chem 286: 43596-43600, 2011.

8. Lahouassa H, Daddacha W, Hofmann H, Ayinde D, Logue EC, Dragin L, Bloch N, Maudet C, Bertrand M, Gramberg T, et al: SAMHD1 restricts the replication of human immunodeficiency virus type 1 by depleting the intracellular pool of deoxynucleoside triphosphates. Nat Immunol 13: 223-228, 2012.

9. Ryoo J, Choi J, Oh C, Kim S, Seo M, Kim SY, Seo D, Kim J, White TE, Brandariz-Nuñez A, et al: The ribonuclease activity of SAMHD1 is required for HIV-1 restriction. Nat Med 20: 936-941, 2014

10. White TE, Brandariz-Nuñez A, Valle-Casuso JC, Amie S, Nguyen L, Kim B, Brojatsch J and Diaz-Griffero F: Contribution of SAM and HD domains to retroviral restriction mediated by human SAMHD1. Virology 436: 81-90, 2013.

11. Gramberg T, Kahle T, Bloch N, Wittmann S, Müllers E, Daddacha W, Hofmann H, Kim B, Lindemann D and Landau NR: Restriction of diverse retroviruses by SAMHD1. Retrovirology 10: 26, 2013.

12. Sze A, Belgnaoui SM, Olagnier D, Lin R, Hiscott J and van Grevenynghe J: Host restriction factor SAMHD1 limits human $\mathrm{T}$ cell leukemia virus type 1 infection of monocytes via STING-mediated apoptosis. Cell Host Microbe 14: 422-434, 2013.

13. Hollenbaugh JA, Gee P, Baker J, Daly MB, Amie SM, Tate J, Kasai N, Kanemura Y, Kim DH, Ward BM, et al: Host factor SAMHD1 restricts DNA viruses in non-dividing myeloid cells. PLoS Pathog 9: e1003481, 2013.
14. Kim ET, White TE, Brandariz-Núñez A, Diaz-Griffero F and Weitzman MD: SAMHD1 restricts herpes simplex virus 1 in macrophages by limiting DNA replication. J Virol 87: 12949-12956, 2013.

15. Chen Z, Zhu M, Pan X, Zhu Y, Yan H, Jiang T, Shen Y, Dong X, Zheng N, Lu J, et al: Inhibition of Hepatitis B virus replication by SAMHD1. Biochem Biophys Res Commun 450: 1462-1468, 2014.

16. Yang S, Shan T, Zhou Y, Jiang Y, Tong W, Liu F, Wen F, Zhang Q and Tong G: Molecular cloning and characterizations of porcine SAMHD1 and its roles in replication of highly pathogenic porcine reproductive and respiratory syndrome virus. Dev Comp Immunol 47: 234-246, 2014.

17. Harris RS, Hultquist JF and Evans DT: The restriction factors of human immunodeficiency virus. J Biol Chem 287: 40875-40883, 2012.

18. Ivashkiv LB and Donlin LT: Regulation of type I interferon responses. Nat Rev Immunol 14: 36-49, 2014.

19. Fink K and Grandvaux N: STAT2 and IRF9: Beyond ISGF3. JAKSTAT 2: e27521, 2013.

20. Sarkis PT, Ying S, Xu R and Yu XF: STAT1-independent cell type-specific regulation of antiviral APOBEC $3 \mathrm{G}$ by IFN-alpha. J Immunol 177: 4530-4540, 2006.

21. Zhang F, Shang D, Zhang Y and Tian Y: Interleukin-22 suppresses the growth of A498 renal cell carcinoma cells via regulation of STAT1 pathway. PLoS One 6: e20382, 2011.

22. Fink K, Martin L, Mukawera E, Chartier S, De Deken X, Brochiero E, Miot F and Grandvaux N: IFN $\beta / T N F \alpha$ synergism induces a non-canonical STAT2/IRF9-dependent pathway triggering a novel DUOX2 NADPH oxidase-mediated airway antiviral response. Cell Res 23: 673-690, 2013

23. Tsuno T, Mejido J, Zhao T, Schmeisser H, Morrow A and Zoon KC: IRF9 is a key factor for eliciting the antiproliferative activity of IFN-alpha. J Immunother 32: 803-816, 2009.

24. Schmittgen TD1 and Livak KJ: Analyzing real-time PCR data by the comparative C (T) method. Nat Protoc 3:1101-1108, 2008.

25. Chen H, Wang LW, Huang YQ and Gong ZJ: Interferon-alpha induces high expression of APOBEC $3 \mathrm{G}$ and STAT-1 in vitro and in vivo. Int J Mol Sci 11: 3501-3512, 2010.

26. Berger A, Sommer AF, Zwarg J, Hamdorf M, Welzel K, Esly N, Panitz S, Reuter A, Ramos I, Jatiani A, et al: SAMHD1-deficient CD14+ cells from individuals with Aicardi-Goutières syndrome are highly susceptible to HIV-1 infection. PLoS Pathog 7: e1002425, 2011.

27. Goujon C, Schaller T, Galão RP, Amie SM, Kim B, Olivieri K, Neil SJ and Malim MH: Evidence for IFNa-induced, SAMHD1-independent inhibitors of early HIV-1 infection. Retrovirology 10: 23, 2013.

28. St Gelais C, de Silva S, Amie SM, Coleman CM, Hoy H, Hollenbaugh JA, Kim B and Wu L: SAMHD1 restricts HIV-1 infection in dendritic cells (DCs) by dNTP depletion, but its expression in DCs and primary CD4+ T-lymphocytes cannot be upregulated by interferons. Retrovirology 9: 105, 2012.

29. Zhang Q, Wang Y, Wei L, Jiang D, Wang JH, Rao HY, Zhu L, Chen H, Fei R and Cong X: Role of ISGF3 in modulating the anti-hepatitis B virus activity of interferon-alpha in vitro. J Gastroenterol Hepatol 23: 1747-1761, 2008.

30. Lehtonen A, Matikainen S and Julkunen I: Interferons up-regulate STAT1, STAT2, and IRF family transcription factor gene expression in human peripheral blood mononuclear cells and macrophages. J Immunol 159: 794-803, 1997.

31. Tenoever BR, Ng SL, Chua MA, McWhirter SM, García-Sastre A and Maniatis T: Multiple functions of the IKK-related kinase IKKepsilon in interferon-mediated antiviral immunity. Science 315: 1274-1278, 2007. 